Check for updates

Cite this: RSC Adv., 2018, 8, 2804

\title{
Effect of silver nitrate on the thermal processability of poly(vinyl alcohol) modified by water
}

\author{
Qing Liu, (D) a Ning Chen, ${ }^{a}$ Shibing Bai (D) *a and Wenzhi Li ${ }^{b}$
}

The thermal processing of poly(vinyl alcohol) (PVA) is a big challenge worldwide. In this article, silver nitrate $\left(\mathrm{AgNO}_{3}\right)$, which can combine with the hydroxyl groups of PVA and water, was introduced to further improve the thermal processability of the poly(vinyl alcohol)/water system. The water states, thermal performance, and rheological properties of PVA modified by $\mathrm{AgNO}_{3}$ were investigated. The results showed that with the increasing of $\mathrm{AgNO}_{3}$ content, the content of bound water in system increased ascribing to the interaction among PVA, water and $\mathrm{AgNO}_{3}$, indicating that the bondage of PVA matrix on water enhanced, thus retarding the tempestuous evaporation of water in system during melt process and making more water remain in system to play the role of plasticizer. Meanwhile, that $\mathrm{AgNO}_{3}$ combined with the hydroxyl groups of PVA further weakened the self-hydrogen bonding of PVA, guaranteeing a lower melting point and higher decomposition temperature, and broadening the thermal processing window. The rheological properties of the modified PVA system showed that the torque and die pressure of the modified PVA system turned to stabilization during melt processing, testifying that the thermal processability of the PVA/water system was largely improved.

Received 1st December 2017

Accepted 7th January 2018

DOI: 10.1039/c7ra12941f

rsc.li/rsc-advances decomposition temperature of PVA. The common plasticizers for modifying PVA are water, ${ }^{\mathbf{1 , 9}, \mathbf{1 0}}$ polyols, ${ }^{\mathbf{9}, 11-13}$ amides, ${ }^{\mathbf{9}, 14}$ esters, ${ }^{\mathbf{1 0}}$ metal salts, ${ }^{15,16}$ etc. These plasticizers could form hydrogen bonding with -OH of PVA, decrease the original inter and/or intra-molecular hydrogen bonding of PVA and then destroy the structural regularity and degree of crystallinity, making the melting point of PVA decrease. ${ }^{1}$ Consequently, thermal processing window is obtained and thermal processing of PVA is able to be realized. Water is popular and most suitable one for PVA because of its clear and low cost. But it, whose boiling point is low $\left(\sim 100{ }^{\circ} \mathrm{C}\right)$, is easy to evaporate and cause unstable flow even foaming during thermal processing. Therefore, how to control water evaporation and further decrease the interaction between PVA molecules are quite important for the stable thermal process of water plasticized PVA. Wang et $a .^{17}$ selected boric acid as a modifier to investigate water states and thermal processability of modified PVA, getting that boric acid inhibited the intense water evaporation during the melting process and improved the processing stability of modified PVA. However, boric acid cannot be easily got rid of and has poisonousness. ${ }^{18}$

$\mathrm{Ag}^{+}$would vanish and turn into $\mathrm{Ag}$ nanoparticles when heating ${ }^{19}$ or UV irradiating, ${ }^{20}$ which endow PVA/Ag composites with antibacterial property, ${ }^{21}$ optical applications, ${ }^{20}$ biosensors $^{22}$ and so on. Besides, $\mathrm{Ag}^{+}$contains several vacant orbital, which could help $\mathrm{Ag}^{+}$adopt lone pair electrons. ${ }^{19,23-25} \mathrm{So}, \mathrm{Ag}^{+}$ owns capacity to adopt electrons provided by hydroxyl-oxygen atom of PVA and water. Huang et al. ${ }^{25}$ indicated that $\mathrm{Ag}^{+}$ could combine with two hydroxyl of PVA and form PVA- $\mathrm{Ag}^{+}$ chelate, this structure destroy the original inter and/or intra-
${ }^{a}$ State Key Laboratory of Polymer Materials Engineering, Polymer Research Institute of Sichuan University, Chengdu 610065, China. E-mail: baishibing@scu.edu.cn; Fax: +86-28-85402465; Tel: +86-28-85405136

${ }^{b}$ State Key Laboratory of Special Functional Water Proof Materials, Beijing Oriental Yuhong Waterproof Technology Co., Ltd, Beijing 100000, China 
molecular hydrogen bonding of PVA and weaken intermolecular forces, eventually reducing its melting point. Furthermore, some $\mathrm{Ag}^{+}$also could combine with water to form $\mathrm{H}_{2} \mathrm{O}-\mathrm{Ag}^{+}$ chelate which could constrain water and even urge more water to play the role of plasticizer. In this work, $\mathrm{AgNO}_{3}$ was adopted as a modifier and its effects on stability of water and thermal processability of water plasticized PVA were systematically tested by DSC, rheology test and SEM analysis.

\section{Experimental}

\subsection{Materials}

Poly(vinyl alcohol) 1799 (GB12010-89, degree of polymerisation $=1750 \pm 50$, hydrolysis degree $=99.9 \mathrm{~mol} \%$ ) were provided by Sichuan Vinylon Works, SINOPEC (China). It was washed several times with deionized water until a $\mathrm{pH}$ of 7 and then dried at $70{ }^{\circ} \mathrm{C}$ in a vacuum oven. Silver nitrate $\left(\mathrm{AgNO}_{3}, \geq 99.8 \%\right)$ was purchased from Chengdu Kelong Chemical Reagent Factory of China. Deionized water was used throughout the experiment.

\subsection{Preparation of modified PVA}

Put $\mathrm{AgNO}_{3}$ aqueous solution into a certain amount of dried PVA and let the solution completely seep into PVA at ambient temperature in a sealed vessel to prepare modified PVA. The weight of dried PVA and deionized water were constant, while the weight of $\mathrm{AgNO}_{3}$ was $0 \mathrm{~g}, 0.1 \mathrm{~g}, 0.5 \mathrm{~g}, 1 \mathrm{~g}$ per $100 \mathrm{~g}$ dried PVA and noting the modified PVA containing various $\mathrm{AgNO}_{3}$ amounts as m-P0, m-P0.1, m-P0.5, m-P1, respectively.

\subsection{Analytical methods}

FT-IR spectras of the molecular structure were recorded on a Nicolet 6700 FT-IR spectrometer (Thermo Nicolet Ltd, Vernon Hills, IL, USA).

Curves of differential scanning calorimetry (DSC) were performed on a TA Q20 differential scanning calorimeter (TA Instruments, USA) under a flowing $\mathrm{N}_{2}$ with sample weighty about $6 \mathrm{mg}$. The samples were first cooled to $-40{ }^{\circ} \mathrm{C}$ with liquid nitrogen, and then heated to $40{ }^{\circ} \mathrm{C}$ at a heating rate of $5{ }^{\circ} \mathrm{C} \min ^{-1}$. The thermal properties of modified PVA were also measured by heating from $40{ }^{\circ} \mathrm{C}$ to $255^{\circ} \mathrm{C}$ at a heating rate of $10{ }^{\circ} \mathrm{C} \min ^{-1}$.

The torque and die pressure of modified PVA were measured on torque rheometer (RM-200C, Harbin Hapro electrical technology CO. LTD. Harbin China). The temperature was set at $100{ }^{\circ} \mathrm{C}, 150{ }^{\circ} \mathrm{C}$ and $150{ }^{\circ} \mathrm{C}$, respectively.

The morphology of liquid-nitrogen-cryofractured section of specimens and the surface appearance of the extrudater were performed on scanning electron microscope (SEM) (FEI Instrument Co. Ltd, USA).

\section{Results and discussion}

\subsection{Interactions in silver nitrate modified PVA system}

The FTIR-ATR spectra of modified PVA with varying $\mathrm{AgNO}_{3}$ content were given in Fig. 1. The wide absorption peak appeared in each FTIR curve in the region of $3000 \mathrm{~cm}^{-1}$ to $3600 \mathrm{~cm}^{-1}$ could be clearly observed, which corresponds to the overlapping stretching vibration peaks of $\mathrm{O}-\mathrm{H}$ in PVA as well as water. Comparing with the curve of $\mathrm{m}-\mathrm{P} 0$, the hydroxyl stretching peak of m-P0.1 shifted to higher wavenumbers and the peak intensities turned weaker. The researches ${ }^{\mathbf{2 6} 27}$ indicate that the changes of hydrogen bonds would affect the chemical environment of $\mathrm{O}-\mathrm{H}$. Specifically, the building of hydrogen bonds would enhance the peak intensities of peak intensities and this peak would shift to lower wavenumbers. Therefore, the addition of $\mathrm{AgNO}_{3}$ weakened the original hydrogen bonds of m-P0. Besides, with the increase of $\mathrm{AgNO}_{3}$ content, the position of this peak changed little, while its intensity gradually weakened, indicating that the addition of $\mathrm{AgNO}_{3}$ did not change the hydrogen bonding types in system, but decreased its numbers.

The metal salt silver ion $\left(\mathrm{Ag}^{+}\right)$has vacant orbital ${ }^{19,23-25}$ which makes it adopt lone pair electrons. So, $\mathrm{Ag}^{+}$owns capacity to adopt the oxygen atom on the hydroxyl which were supplied by PVA and water, which makes it possible to combine with hydroxyl oxygen of water and PVA. Huang et al. ${ }^{25}$ indicated that $\mathrm{Ag}^{+}$could combine with two hydroxyl of PVA, showed in Fig. 2. Therefore, in this PVA/water/AgNO 3 system, PVA chelated $\mathrm{Ag}^{+}$to destroy the hydrogen bonds of PVA, resulting in the changes of the peak of $\mathrm{O}-\mathrm{H}$, showed in Fig. 1. Moreover, some $\mathrm{Ag}^{+}$also could combine with water to form $\mathrm{H}_{2} \mathrm{O}-\mathrm{Ag}^{+}$chelate. Therefore, the interactions in this $\mathrm{PVA} /$ water/ $/ \mathrm{AgNO}_{3}$ system could be clearly presented in Fig. 3. $\mathrm{AgNO}_{3}$ combines with PVA together with water to build the chelates to break the self-hydrogen bonding of PVA and urge more water to play the role of plasticizer.

\subsection{Water states in the modified PVA}

The key to realize thermal processing and melt spinning of water modified PVA steadily is to avoid water rapidly evaporating. And it should be underlined that the evaporation behavior of water is closely related to water states in the modified PVA.

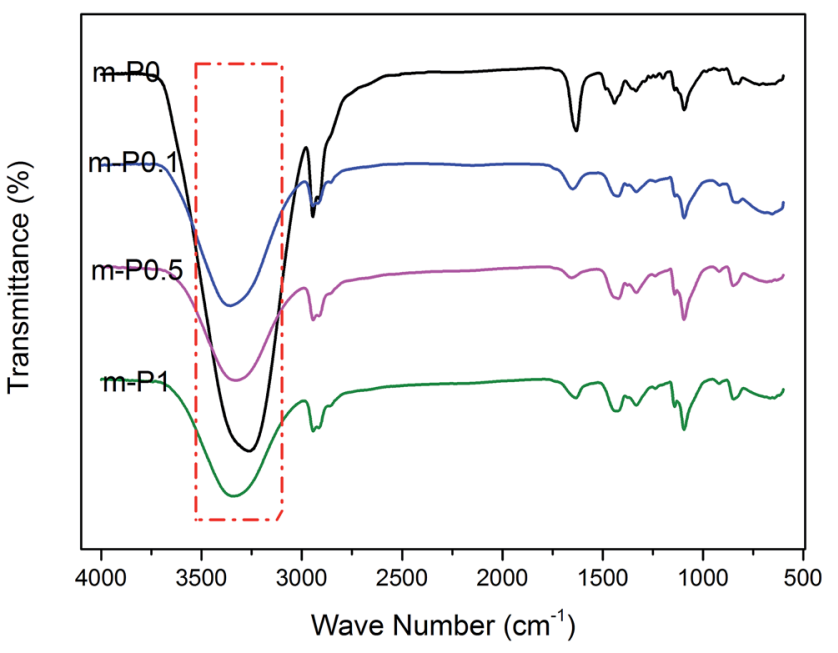

Fig. 1 FTIR spectra of PVA/water with different $\mathrm{AgNO}_{3}$ content. 
<smiles></smiles>

Fig. 2 Structure for PVA-Ag ${ }^{+}$chelate proposed by Huang et al. ${ }^{25}$

Generally, water has three different associating states ${ }^{\mathbf{1 , 2 8}}$ with hydrophilic polymers, i.e., free water, freezable bound water and non-freezing water. Compared with free water, having no interaction with PVA molecules and own the same melting point as pure water, freezable bound water has less closely association with hydroxy groups and its melting point is below $0{ }^{\circ} \mathrm{C}$. Non-freezing water has directly interacting with the polar groups of hydrophilic polymer which have no detectable phase transition in the range of $-40{ }^{\circ} \mathrm{C}$ to $20^{\circ} \mathrm{C}$. Both of them are also named as bound water. Accordingly, if the content of bound water in PVA can be increased, stable melt process should certainly be realized.

The states of water could be differentiated by low temperature differential scanning calorimetric (DSC) measurements, as shown in Fig. 4. Apparently, the pure PVA had none peak within the above cited range of temperatures, which indicated that pure PVA had no phase transformation occurred during this heating period. And the pure water had one intensely phase transformation peak corresponding to the melting point of ice water. Besides, the modified PVA had two visible endothermic peaks appeared in DSC curve at about $T=-10{ }^{\circ} \mathrm{C}$ and $T=0{ }^{\circ} \mathrm{C}$, which indicated that there existed more than two different kinds of water. The endothermic peak at lower temperature belonged to the phase transformation of freezable bound water, signing as peak $\mathrm{fb}_{\mathrm{fb}}$, and the other one at higher temperature which overlapped with the phase transformation peak of pure water belonged to the phase transformation of free water, signing as peak $\mathrm{k}_{\mathrm{f}}$. The curves showed that the peak intensity of peak $\mathrm{fb}_{\mathrm{fb}}$ strengthened visibly once adding $\mathrm{AgNO}_{3}$, besides, with the increase of $\mathrm{AgNO}_{3}$ content, the peak intensity of peak $\mathrm{fb}_{\mathrm{f}}$ enhanced substantially. Not only that, but the peak $\mathrm{fb}_{\mathrm{fb}}$ moved toward the direction of higher temperature as the amounts of $\mathrm{AgNO}_{3}$ increased.

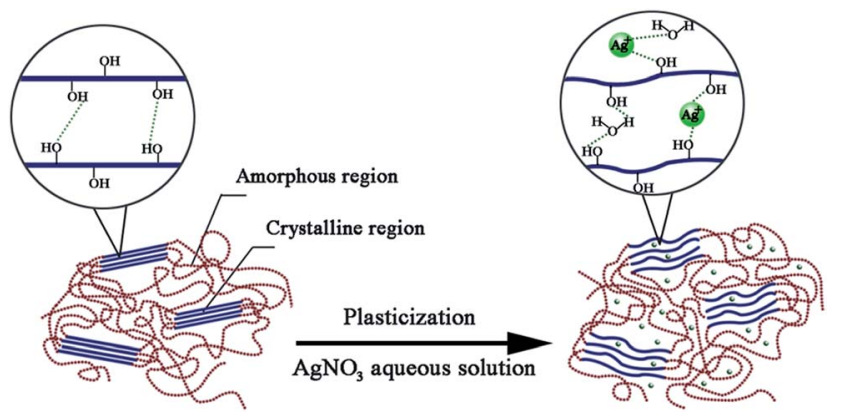

Fig. 3 Schematic structures of water and silver nitrate in modified PVA.

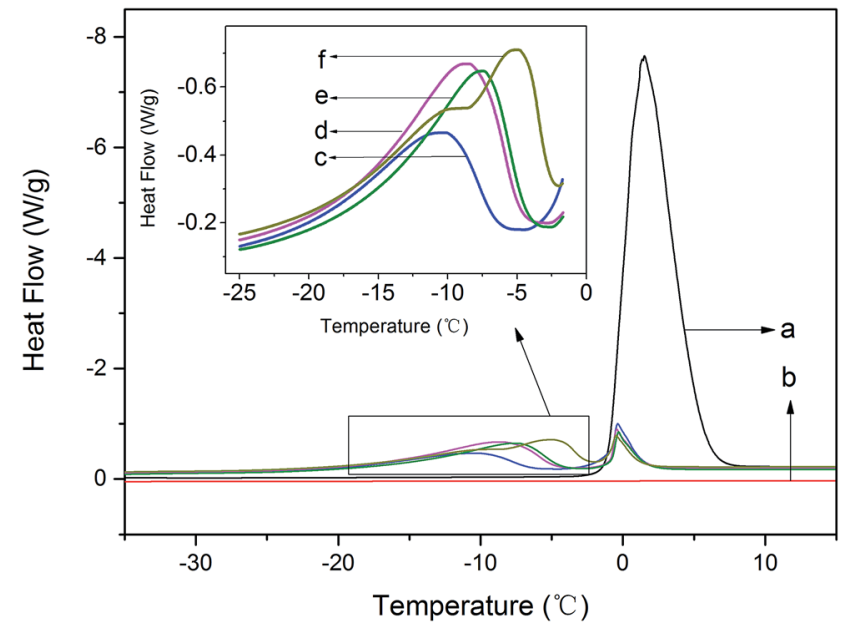

Fig. 4 The heating curves of modified PVA: (a) deionized water; (b) pure PVA; (c) m-P0; (d) m-P0.1; (e) m-P0.5; (f) m-P1.

To further explore the change of water states, the values of melting point $(T)$ and melting enthalpy $(-\Delta H)$ of the modified PVA containing various $\mathrm{AgNO}_{3}$ amounts were recorded in Table 1. Observably, the melting enthalpy of peak $\mathrm{fb}_{\mathrm{fb}}$ and peak $\mathrm{k}_{\mathrm{f}}$ changed with the amounts of $\mathrm{AgNO}_{3}$ increasing, that of freezable bound water increased from $32.3 \mathrm{~J} \mathrm{~g}^{-1}$ to $51.5 \mathrm{~J} \mathrm{~g}^{-1}$ and that of free water decreased from $18.0 \mathrm{~J} \mathrm{~g}^{-1}$ to $8.7 \mathrm{~J} \mathrm{~g}^{-1}$. Those results illustrated that the content of freezable bound water and free water which existed in modified PVA have changed with the amounts of $\mathrm{AgNO}_{3}$ increasing, in other words, $\mathrm{AgNO}_{3}$ has affected the water states of PVA/water system.

Furthermore, the weight of free water and freezable bound water of modified PVA could be calculated ${ }^{28}$ by the following equation eqn (1).

$$
W_{\mathrm{n}}=\frac{W_{\mathrm{s}} \Delta H_{\mathrm{n}}}{\Delta H_{\mathrm{o}}}
$$

where $W_{\mathrm{n}}$ means the weight of vary types water of modified PVA; $W_{\mathrm{s}}$ was the weight of modified PVA; $\Delta H_{\mathrm{n}}$ means the melting enthalpy of vary types water of modified PVA; $\Delta H_{\mathrm{o}}$ means the melting enthalpy of ice water.

Besides, the weight of non-freezing water of modified PVA could be calculated by the following equation eqn (2) because

Table 1 The values of melting point and ice-melting enthalpy obtained from the DSC curves analysis ${ }^{a}$

\begin{tabular}{lllllr}
\hline & $W_{\mathrm{s}}(\mathrm{mg})$ & $T_{\mathrm{fb}}\left({ }^{\circ} \mathrm{C}\right)$ & $\begin{array}{l}-\Delta H_{\mathrm{fb}} \\
\left(\mathrm{J} \mathrm{g}^{-1}\right)\end{array}$ & $T_{\mathrm{f}}\left({ }^{\circ} \mathrm{C}\right)$ & $\begin{array}{r}-\Delta H_{\mathrm{f}} \\
\left(\mathrm{J} \mathrm{g}^{-1}\right)\end{array}$ \\
\hline $\begin{array}{llllr}\text { Pure } \\
\text { water }\end{array}$ & 5.4 & - & - & 1.5 & 340.8 \\
m-P0 & 7.2 & -11.0 & 32.3 & -0.4 & 18.0 \\
m-P0.1 & 7.1 & -8.9 & 50.9 & -0.4 & 12.3 \\
m-P0.5 & 7.6 & -7.8 & 47.0 & -0.3 & 12.0 \\
m-P1 & 7.4 & -5.4 & 51.5 & -0.5 & 8.7
\end{tabular}

${ }^{a} W_{\mathrm{s}}$ : weight of modified PVA; $T_{\mathrm{fb}}$ : the melting point of freezable bound water; $\Delta H_{\mathrm{fb}}$ : melting enthalpy of freezable bound water; $T_{\mathrm{f}}$ : the melting point of free water; $\Delta H_{\mathrm{f}}$ : melting enthalpy of free water. 
Table 2 The weight and content of vary types water of modified PVA ${ }^{a}$

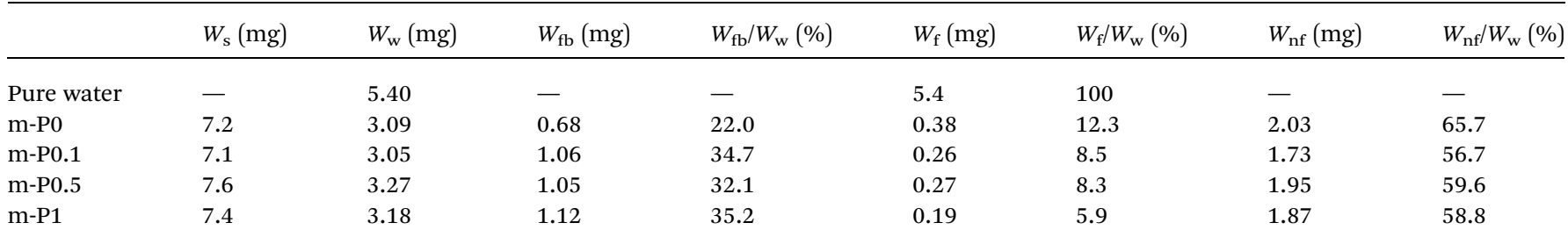

${ }^{a} W_{\mathrm{s}}$ : weight of modified PVA; $W_{\mathrm{w}}$ : weight of water in modified PVA; $W_{\mathrm{fb}}$ : weight of freezable bound water; $W_{\mathrm{f}}$ : weight of free water; $W_{\mathrm{nf}}:$ weight of non-freezing water.

the total water in modified PVA consists of free water, freezable bound water and non-freezing water.

$$
W_{\mathrm{nf}}=W_{\mathrm{w}}-W_{\mathrm{f}}-W_{\mathrm{fb}}
$$

where $W_{\text {nf }}$ means the weight of non-freezing water of modified PVA; $W_{\mathrm{w}}$ means the weight of water of modified PVA; means $W_{\mathrm{f}}$ the weight of free water of modified PVA; $W_{\mathrm{fb}}$ means the weight of freezable bound water of modified PVA.

The weight and content of vary types water of modified PVA which were calculated by eqn (1) and (2) were listed in the following Table 2 .

It can be found from Table 2 that the content of freezable bound water and free water which existed in modified PVA did change when adding $\mathrm{AgNO}_{3}$. The content of freezable bound water increased from $22.0 \%$ to $34.7 \%$, the content of free water decreased from $12.3 \%$ to $8.5 \%$ once adding $\mathrm{AgNO}_{3}$. Especially, the content of non-freezing water showed downtrend, rapidly decreased from $65.7 \%$ to $56.7 \%$ when adding $\mathrm{AgNO}_{3}$. Besides, the content of the three type water continued to change with the amounts of $\mathrm{AgNO}_{3}$ increasing.

Fig. 5 presented one kind of schematic structures of water in modified PVA system. Shown as Fig. 5(a), when slowly poured into PVA matrix, the water molecules would easily permeate PVA chain segments and preferentially combine with hydroxyl of PVA, developing the first water layer, this part water is nonfreezing water. When added water reached this level that the combined points of the hydroxyl of PVA turned saturated, the hydrogen bond between water molecules and PVA were not formed any longer, the following water would combine with hydroxyl of the first water layer, developing the second and even more water layer, this part water called freezable bound water. With added water content continuing to increase, the water layer turn more, the PVA molecules did not restrain water any longer, there water showed almost no difference with pure water.

Fig. 5(b) showed $\mathrm{AgNO}_{3}$ replacing some first water layer to combine with the hydroxyl of PVA and meanwhile bond with water to form water layers. This schematic structure explained why content of non-freezing water decreased after adding $\mathrm{AgNO}_{3}$. And the interaction energies of $\mathrm{H}_{2} \mathrm{O} \cdots \mathrm{Ag}^{+}$, which is $10.38 \mathrm{Kcal} \mathrm{mol}^{-1},{ }^{29}$ is further greater than that of $\mathrm{H}_{2} \mathrm{O} \cdots \mathrm{H}-\mathrm{OH}$, which is $6.8 \mathrm{Kcal} \mathrm{mol}^{-1},{ }^{30} \mathrm{so} \mathrm{Ag}^{+}$has greater force to bond water, restraining water and making more water layers stable.

The states of water existing in PVA reflected the interaction among water, $\mathrm{Ag}^{+}$and PVA to some extent. Conversely, that $\mathrm{AgNO}_{3}$ combines with PVA and water to build the chelates changed the states of water.

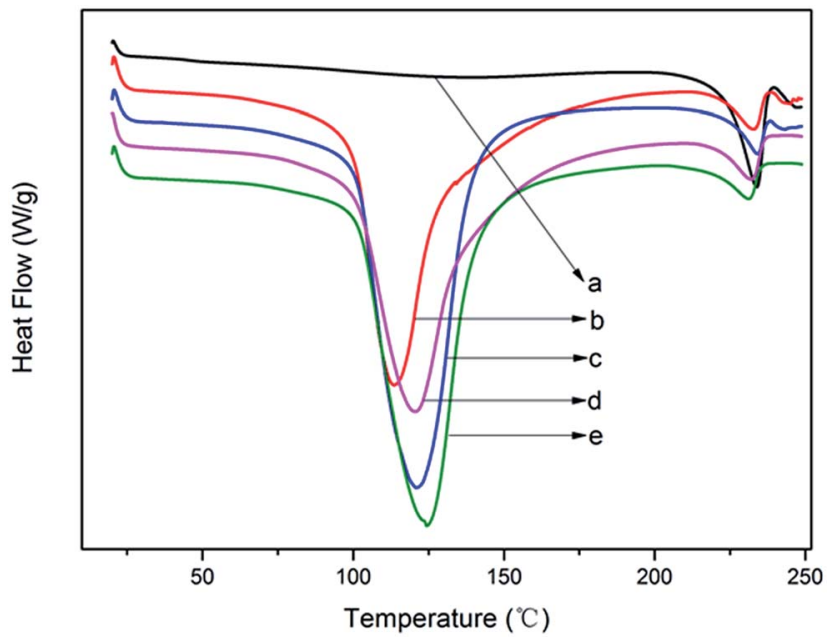

Fig. 6 The heating curves of modified PVA: (a) pure PVA; (b) m-PO; (c) m-P0.1; (d) m-P0.5; (e) m-P1.

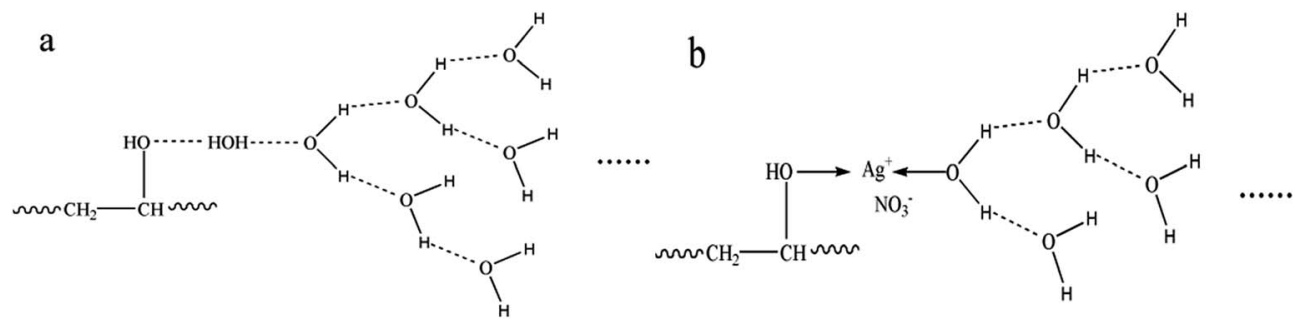

Fig. 5 Schematic structures of water in m-PO (a) and modified PVA system (b). 


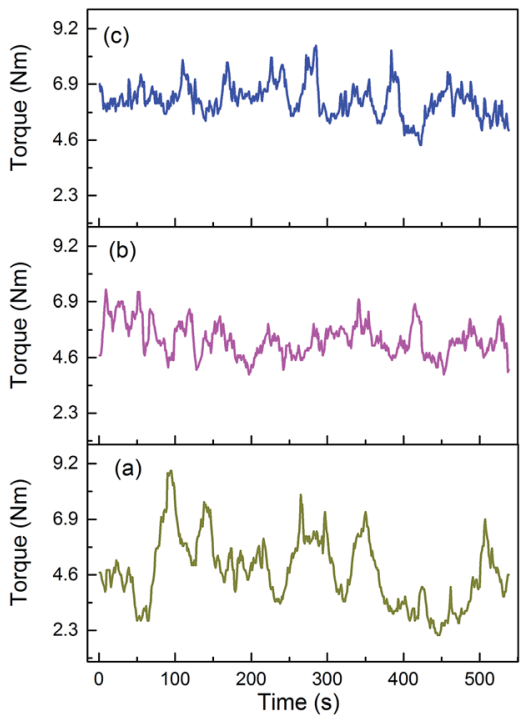

A1

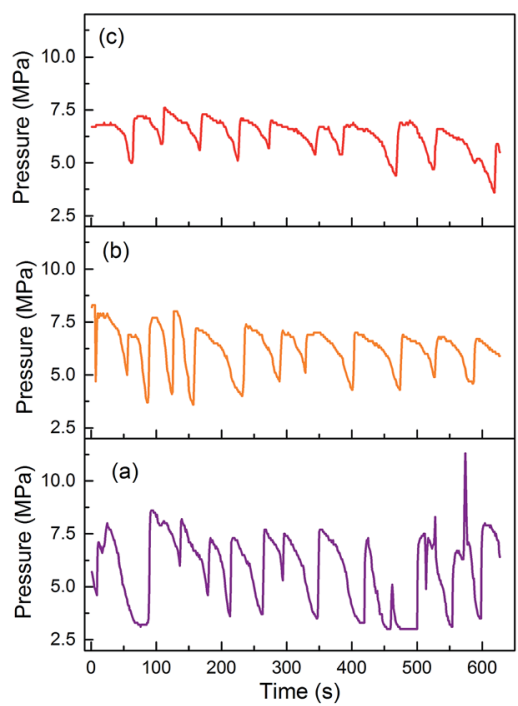

B1

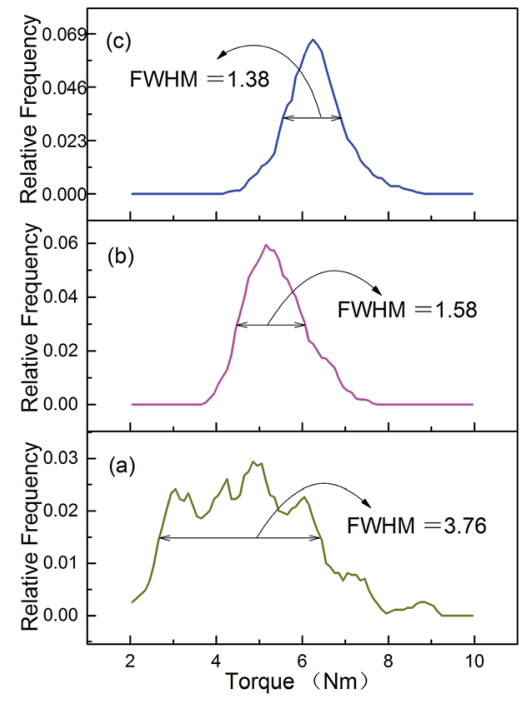

A2

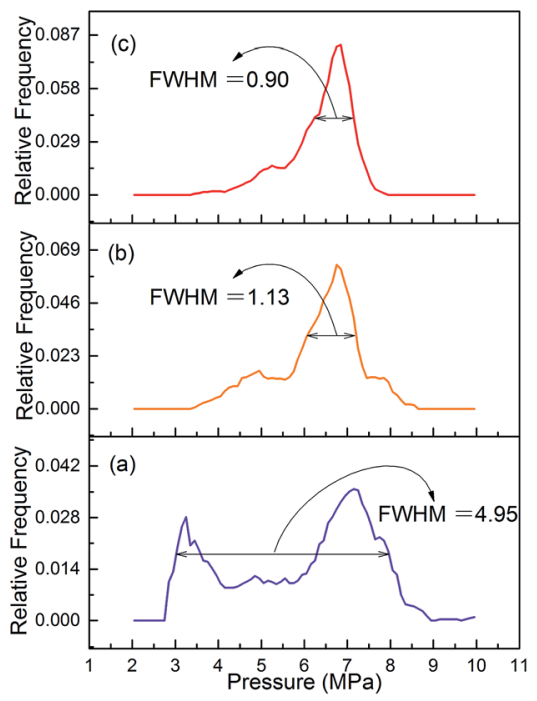

B2

Fig. 7 The torque (A) and die pressure (B) curves of modified PVA: (a) m-P0; (b) m-P0.1; (c) m-P1.

\subsection{The evaporation behavior of water in the modified PVA}

The key to realize thermal processing and melt spinning of modified PVA steadily is to effectively control water evaporation and avoid water acutely evaporating during thermal processing. The above analysis indicated that $\mathrm{Ag}^{+}$has restrained more water to play the role of plasticizer and boosted more freezable bound water and reduced free water, which may affect the evaporation behavior of water.

Fig. 6 depicted the heating curves of modified PVA containing various $\mathrm{AgNO}_{3}$ amounts within the temperature range from $40{ }^{\circ} \mathrm{C}$ to $255^{\circ} \mathrm{C}$. It can be observed from Fig. 7 that the pure PVA had only one peak appeared at around $T=230{ }^{\circ} \mathrm{C}$ which belonged to the melting point of pure PVA. And the other four curves have similar profiles, two visible endothermic peaks can be seen at about $T=120{ }^{\circ} \mathrm{C}$ and $T=230{ }^{\circ} \mathrm{C}$ through the temperature monitored. The endothermic peak at lower temperature belonged to evaporation peak of water of modified PVA, signing as peak $\mathrm{w}_{\mathrm{w}}$ and the other endothermic peak at higher temperature belonged to the melting peak of pure PVA, signing as peak $\mathrm{p}_{\mathrm{p}}$. As is showed in Fig. 7, the peak $\mathrm{w}_{\mathrm{w}}$ moved to high temperature with the increase of $\mathrm{AgNO}_{3}$ content, the value of $\mathrm{m}$ P0 was $113.5^{\circ} \mathrm{C}$, and that of m-P1 was $124.7^{\circ} \mathrm{C}$, increasing by $11.2^{\circ} \mathrm{C}$ in comparison to $\mathrm{m}-\mathrm{P} 0$. That is to say, the boiling point of water was indeed increased and the water which existed in modified PVA would be evaporated in higher temperature when $\mathrm{AgNO}_{3}$ was used to modify PVA. Besides, the peak $\mathrm{w}_{\mathrm{w}}$ shape was broadened under the effect of $\mathrm{AgNO}_{3}$, meaning that water would be evaporated in the broad temperature range, this is beneficial 
to avoiding the formation of bubbles during thermal processing caused by the rapid evaporation of water. Therefore, under the influence of $\mathrm{AgNO}_{3}$, the evaporation behavior of water has been markedly improved.

\subsection{Processing properties of modified PVA}

The improved evaporation behavior of water would avoid its rapid evaporation and stabilize melts during thermal processing under the temperature of $150{ }^{\circ} \mathrm{C}$, and then improve the thermal processing properties of modified PVA, which could be intuitively characterized by the changes of torque and die pressure during processing and the morphology of products.

The differences in the thermal processing rheological behaviors for modified PVA containing various $\mathrm{AgNO}_{3}$ amounts were reflected by the torque and die pressure. From Fig. 7(A1), it can be seen that the three torque curves all looked fluctuant to some extent, indicating that these melts were in a state of dynamic instability during thermal processing. The torque of m-P0 changed from $2.1 \mathrm{Nm}$ to $8.9 \mathrm{Nm}$, fluctuating acutely. Whereas the value of torque turned placid once adding $\mathrm{AgNO}_{3}$ into PVA/water system, the torque of m-P0.1 and m-P1 changed from $3.9 \mathrm{Nm}$ to $7.4 \mathrm{Nm}$, and that of $\mathrm{m}-\mathrm{P} 1$ changed from $4.4 \mathrm{Nm}$ to $8.5 \mathrm{Nm}$. Besides, Fig. 7(A2) showed the discrete distribution curves of torque, it can be clearly seen that these three discrete distribution curves looked like normal distribution which is the classic bell curve and the full width half maximum (FWHM) of $\mathrm{m}-\mathrm{P} 0$ is $3.76 \mathrm{Nm}$, further exceeding that of $\mathrm{m}-\mathrm{P} 0.1$ or $\mathrm{m}-\mathrm{P} 1$. The results indicated that the addition of $\mathrm{AgNO}_{3}$ reduced the dispersion degree of torque and then made the melts more stable. The die pressure (Fig. 7(B)) had similar notable difference. Especially, the discrete distribution curve of $\mathrm{m}-\mathrm{P} 0$, learning from Fig. 7(B2), showed two peaks. The results illustrated that the die pressure changed acutely and the melts were in unstable state when only using water to modify PVA. Obviously, the addition of $\mathrm{AgNO}_{3}$ made the melts stable in large extent and greatly changed the rheological properties and favored the thermal processing.

The morphology of extruded strips could intuitively reflect processability of composite materials. Fig. 8(a)-(c) showed the morphology of liquid-nitrogen-cryofractured section of

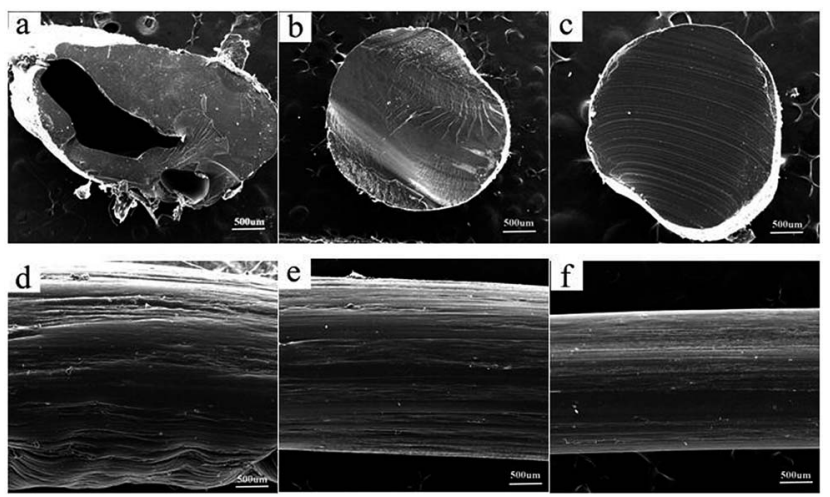

Fig. 8 The morphology of extruded strips of modified PVA: (a) and (d) m-P0; (b) and (e) m-P0.1; (c) and (f) m-P1. extruded strips of modified PVA. Obviously, pores structures were only observed in Fig. 8(a), while the other two micromorphology were continuous and compact. Fig. 8(d)-(f) described the surface appearance of the extrudater of modified PVA. It can be seen from Fig. 8 that the outlooks of the extruded strips of $\mathrm{m}-\mathrm{P} 0.1$ and $\mathrm{m}-\mathrm{P} 1$ were smooth, homogenous comparing with that of $\mathrm{m}-\mathrm{P} 0$.

From the above results, further explanation can be given for the changes of thermal processing rheological behaviors of modified PVA. There is unavoidable that water would evaporate from the melts and then labilize the melts during extruding process. The addition of $\mathrm{AgNO}_{3}$ improved water evaporation behavior and avoided the melts unstable flow to some extent. Noticeably, during the practical processing, modified PVA is melted in a relative hermetic condition, e.g. in an extruder. The strong pressure induced by the rotation of screw will further inhibit the evaporation of water in modified PVA. As a result, more water remains in modified PVA acting as an effective plasticiser.

Substantially, the results benefited from the effect of $\mathrm{Ag}^{+}$, the addition of $\mathrm{AgNO}_{3}$ improved water evaporation behavior and avoided the melts unstable flow and generating bubbles which were brought about by water rapidly evaporation the during extruding process.

\section{Conclusion}

In summary, $\mathrm{Ag}^{+}$has changed water states and retarded its tempestuous evaporation, urging further more water to remain in system to play the role of plasticizer. Meanwhile, that $\mathrm{AgNO}_{3}$ combined with the hydroxyl groups of PVA further weakened the self-hydrogen bonding of PVA, guaranteeing a lower melting point and higher decomposition temperature and broadening thermal processing window and optimizing thermal processability. The thermoplastic processing performance was characterized by rheology test that the value of torque and die pressure during melt processing of PVA turned placid with the increase of $\mathrm{AgNO}_{3}$ content which indicated that the melts turn to be stable under the effect of metal salt $\mathrm{Ag}^{+}$. The SEM showed that the micro-morphology of extruded strips which were modified by both water and $\mathrm{AgNO}_{3}$ turned smoother, more homogenous and continuous comparing with that only modified by water, intuitively manifesting that the addition of $\mathrm{AgNO}_{3}$ optimized thermoplastic processing performance of PVA/water system.

\section{Conflicts of interest}

There are no conflicts to declare.

\section{Acknowledgements}

This work was financially supported by National Natural Science Foundation of China $(51573117,51433006)$, Science and technology support program of Sichuan Province (2015GZ0067) and State key laboratory polymer materials engineering (No. sklpme2016-3-01). 


\section{References}

1 N. Chen, L. Li and Q. Wang, Plast., Rubber Compos., 2007, 36, 283-290.

2 D. Minelga, K. UkvalbergienE், A. BaltruŠAitis and G. BalČIŪNas, Mater. Sci., 2013, 19, 164-168.

3 N. Tudorachi and R. Lipsa, J. Appl. Polym. Sci., 2011, 122, 1109-1120.

4 L. Cui, J.-T. Yeh, K. Wang and Q. Fu, J. Polym. Sci., Part B: Polym. Phys., 2008, 46, 1360-1368.

5 D. S. Vicentini, A. Smania and M. C. M. Laranjeira, Mater. Sci. Eng. C, 2010, 30, 503-508.

6 N. Sinha, M. K. Gupta, N. Goel, et al., Phys. B, 2011, 406, 4068-4076.

7 L. Zhang, G. Zhang, J. Lu, et al., Journal of Macromolecular Science: Part D-Reviews in Polymer Processing, 2013, 52, 163167.

8 J. Miao, R. Zhang and R. Bai, J. Membr. Sci., 2015, 493, 654663.

9 R. Wang, Q. Wang and L. Li, Polym. Int., 2003, 52, 1820-1826.

10 P. Liu, W. Chen, Y. Liu, S. Bai and Q. Wang, Polym. Degrad. Stab., 2014, 109, 261-269.

11 X. Ma, J. Yu and K. He, Macromol. Mater. Eng., 2006, 291, 1407-1413.

12 J. Jang and K. L. Dong, Polymer, 2003, 44, 8139-8146.

13 W. Wu, H. Tian and A. Xiang, J. Polym. Environ., 2012, 20, 6369.

14 X. Y. Zhou, Y. F. Cui, D. M. Jia and D. Xie, Polym.-Plast. Technol. Eng., 2009, 48, 489-495.
15 X. Jiang, H. Li, Y. Luo, et al., Int. J. Biol. Macromol., 2016, 82, 223-230.

16 R. F. Bhajantri, V. Ravindrachary, A. Harisha, et al., Polymer, 2006, 47, 3591-3598.

17 N. Wang, L. Zhao, C. Zhang, et al., J. Appl. Polym. Sci., 2016, 133, 43246.

18 D. Teshima, T. Taniyama and R. Oishi, J. Clin. Pharm. Ther., 2001, 26, 387-390.

19 Y. Gan, S. Bai, S. Hu, X. Zhao and Y. Li, RSC Adv., 2016, 6, 56728-56737.

20 R. P. Chahal, S. Mahendia, A. K. Tomar, et al., Appl. Surf. Sci., 2015, 343, 160-165.

21 K. H. Hong, J. L. Park, I. H. Sul, et al., J. Polym. Sci., Part B: Polym. Phys., 2010, 44, 2468-2474.

22 C. Marega, J. Maculan, R. G. Andrea, et al., Nanotechnology, 2015, 26, 075501.

23 K. Akhbari, A. Morsali and P. Retailleau, Polyhedron, 2010, 29, 3304-3309.

24 S. W. Kang, J. Ind. Eng. Chem., 2010, 16, 896-900.

25 C. J. Huang, C. C. Yen and T. C. Chang, J. Appl. Polym. Sci., 1991, 42, 2237-2245.

26 D. K. Buslov, N. I. Sushko and O. N. Tretinnikov, Polym. Sci., Ser. A, 2011, 53, 1121-1127.

27 J. A. Venegas-Sanchez, M. Tagaya and T. Kobayashi, Ultrason. Sonochem., 2014, 21, 295-309.

28 W. Li, F. Xue and R. Cheng, Polymer, 2005, 46, 12026-12031.

29 G. Zhang, X. Zhao and D. Chen, J. Phys. Chem. A, 2013, 117, 10944-10950.

30 A. Avramopoulos, M. G. Papadopoulos and A. J. Sadlej, Chem. Phys. Lett., 2003, 370, 765-769. 